\title{
Nationwide Variability in the Use of Induction Immunosuppression for Adult Heart Transplantation
}

\author{
Carlos Diaz-Castrillon ${ }^{1}$, Laura Seese ${ }^{2}$, Michael Mathier ${ }^{2}$, Mary Keebler $^{2}$, Gavin Hickey ${ }^{2}$, \\ Dennis McNamara ${ }^{1}$, Mark SImon ${ }^{1}$, Ed Horn ${ }^{1}$, and Arman Kilic ${ }^{2}$ \\ ${ }^{1}$ University of Pittsburgh Medical Center \\ ${ }^{2}$ University of Pittsburgh Medical Center Health System
}

June 8, 2020

\begin{abstract}
Background: Institutional factors have been shown to impact outcomes following orthotopic heart transplantation (OHT). This study evaluated center variability in the utilization of induction therapy for OHT and its implications on clinical outcomes. Methods: Adult OHT patients between 2010 and 2018 were identified from the UNOS registry. Transplant centers were stratified based on their rates of induction therapy utilization. Mixed-effects logistic regression models were created with drug-treated rejection within 1-year as primary endpoint and individual centers as random parameter. Risk-adjusted Cox regression was used to evaluate patient-level mortality outcomes. Results: In 17,524 OHTs performed at 100 centers, induction therapy was utilized in $48.6 \%$ ( $\mathrm{n}=8411$ ) with substantial variability between centers (IQR $21.4-79.1 \%$ ). There were 36,30 , and 34 centers in the low $(<29 \%)$, intermediate $(29-66 \%)$, and high $(>67 \%)$ induction utilization terciles groups, respectively. Induction therapy did not account for the observed variability in the treated rejection rate at 1-year among centers after adjusting for donor and recipient factors $(\mathrm{p}=0.20)$. No differences were observed in postoperative outcomes among induction utilization centers groups (all, p $>0.05$ ). Furthermore, there was a weak correlation between the percentage of induction therapy utilization at the centerlevel and recipients found to have moderate $(\mathrm{r}=0.03)$ or high $(\mathrm{r}=0.04)$ baseline risks for acute rejection at 1-year. Conclusions: This analysis demonstrates there is substantial variability in the use of induction therapy among OHT centers. In addition, there was a minimal correlation with baseline recipient risk or 1-year rejection rates, suggesting a need for better-standardized practices for induction therapy use in OHT.
\end{abstract}

\section{Correspondence and Reprint Requests:}

Arman Kilic, M.D.

Division of Cardiac Surgery

University of Pittsburgh School of Medicine

200 Lothrop St

Suite C700

Pittsburgh, PA 15213

Phone: 412-692-5218

E-mail: kilica2@upmc.edu

Abstract 
Background: Institutional factors have been shown to impact outcomes following orthotopic heart transplantation (OHT). This study evaluated center variability in the utilization of induction therapy for OHT and its implications on clinical outcomes.

Methods: Adult OHT patients between 2010 and 2018 were identified from the UNOS registry. Transplant centers were stratified based on their rates of induction therapy utilization. Mixed-effects logistic regression models were created with drug-treated rejection within 1-year as primary endpoint and individual centers as random parameter. Risk-adjusted Cox regression was used to evaluate patient-level mortality outcomes.

Results: In 17,524 OHTs performed at 100 centers, induction therapy was utilized in $48.6 \%$ ( $\mathrm{n}=8411$ ) with substantially variability between centers (IQR $21.4-79.1 \%$ ). There were 36,30 , and 34 centers in the low $(<29 \%)$, intermediate $(29-66 \%)$, and high $(>67 \%)$ induction utilization terciles groups, respectively. Induction therapy did not account for the observed variability in the treated rejection rate at 1-year among centers after adjusting for donor and recipient factors $(\mathrm{p}=0.20)$. No differences were observed in postoperative outcomes among induction utilization centers groups (all, $\mathrm{p}>0.05$ ). Furthermore, there was a weak correlation between the percentage of induction therapy utilization at the center-level and recipients found to have moderate $(\mathrm{r}=0.03)$ or high $(\mathrm{r}=0.04)$ baseline risks for acute rejection at 1-year.

\section{Conclusions:}

This analysis demonstrates that there is substantial variability in the use of induction therapy among OHT centers. In addition, there was minimal correlation with baseline recipient risk or 1-year rejection rates, suggesting a need for better standardized practices for induction therapy use in OHT.

\section{Introduction}

Perioperative high-intensity immunosuppression has the theoretical benefit of reducing the risk of rejection following orthotopic heart transplant (OHT) (1-4), where several contemporary randomized trials that have evaluated the impacts of various induction therapy agents, have also come to disparate conclusions $(5,8)$. Prior studies have demonstrated that patients with higher pre-transplant predicted risks of rejection may garner benefit from receiving induction immunotherapy $(9,10)$. The current guidelines from the International Society of Heart and Lung Transplantation (ISHLT) recommend antibody-based induction immunosuppression as an alternative for patients at high risk of renal dysfunction or rejection (11), although predicting which patients carry sufficient risk remains challenging. Considering this uncertainty, many centers have developed their own protocols for induction therapy utilization. Institutional factors greatly influence outcomes following $\mathrm{OHT}(12,14)$ and may also be key determinants in the likelihood of a patient to receive induction therapy as well as their odds of rejection. As such, our objective was to evaluate the degree of center variability in the utilization of induction therapy and its implications on clinical outcomes following OHT.

\section{Methods}

\section{Data Source}

The United Network for Organ Sharing (UNOS) registry includes deidentified information on preoperative, intra-operative, and post-operative variables from all donors, wait-listed candidates, and transplant recipients in the United States. The University of Pittsburgh Institutional Review Board granted approval for this study.

\section{Study Population}

Adults ([?]18 years) within the UNOS data registry who received a first-time OHT between 2010 and 2018 were included. Exclusion criteria included recipients of multi-visceral transplants, those undergoing redo OHT, centers with less than 45 cumulative transplants during the study period and recipients with more than $20 \%$ missing recipient data. The types of induction therapy evaluated in the study were interleukin 2 (IL2) receptor antagonists (basiliximab and daclizumab) as well as polyclonal and monoclonal anti-thymocyte antibodies (thymoglobulin, atgam, muromonab OKT3 and alemtuzumab). 


\section{Outcomes}

The primary outcome was drug-treated rejection within the first year following OHT. The secondary outcomes included rates of new-onset dialysis, stroke, operative mortality, and survival at 90-days, 1 and 5-years.

\section{Baseline Characteristics}

Baseline waitlist data included age, gender, body mass index (BMI), ethnicity, blood type, etiology of heart failure, pulmonary vascular resistance (PVR), diabetes mellitus status, serum creatinine, dialysis dependence, ventricular assist device support, mechanical ventilation, and class I and II panel reactive antibodies. Donor variables included age, left ventricle ejection fraction, mechanism of death, prior cardiac arrest, diabetes mellitus status, cocaine usage, and smoking history. Donor-recipient matching variables included human leukocyte antigen (HLA) mismatch, ABO blood type match, gender match, race match, cytomegalovirus match and donor-to-recipient weight ratio. A pre-existing 13-point risk score for acute rejection within 1-year of OHT that evaluated the domains of HLA mismatch, ethnicity, age and gender was used to assign baseline predicted preoperative risk of post-OHT rejection for each patient in the study (10). Patients were classified by their cumulative score as low risk (score 0-5 points), intermediate risk (score 6-9 points) and high risk (score [?]10 points)

\section{Statistical analysis}

In order to comparatively assess the effect of center variations, the induction therapy utilization rate was stratified into equal terciles, which were classified as low $(<29 \%)$, intermediate $(29-66 \%)$ or high $(>67 \%)$ induction therapy utilization. The data is described as proportions (\%) for categorical variables and as means or medians for continuous variables, with standard deviation (SD) or interquartile range (IQR), respectively. Pearson's $\mathrm{Chi}^{2}$ test was used to compare categorical variables and one-way analysis of variance (ANOVA) or students t-tests were used to compare continuous data. All statistical tests were 2-sided, and $\mathrm{p}<0.05$ was considered significant. Multilevel mixed-effects logistic regression models were used to estimate the relationship of induction therapy and post-OHT clinical outcomes accounting for inter-center variability. The primary endpoint was drug-treated acute rejection within the first year following OHT. Model A included only the individual transplant centers as random effect parameters. Model B added the recipient and donor risk factors identified as fixed effect parameters to Model A. Finally, Model C, added induction therapy variable as a fixed effect parameter to Model B. Changes in the estimate of the betweencenters variance may suggest the distribution of variables across centers. The Variance Partition Coefficient (VPC) was estimated to evaluate the proportion of variation attributable to systematic differences between centers characteristics in the context of a binary dependent variable. This contribution as a percentage was calculated as $[\mathrm{X} / \mathrm{X}+3.29] * 100$, where $\mathrm{X}$ is the variance estimate from the random effect component of the model (15). Risk-adjusted Cox proportional hazards models were used to evaluate the adjusted impacts of induction therapy on mortality. Kaplan-Meier estimates were used to evaluate the longitudinal impacts of the use of induction therapy on survival. Pearson's correlation coefficient (R) was utilized to assess the correlation between pre-OHT risk scores and the use of induction therapy. All analyses were performed with version 15 STATA statistical software (StataCorp LP, College Station, TX).

\section{Results}

\section{Study Population - Center Characteristics}

A total of 100 centers performed 17,524 OHTs with a mean age of $53.8 \pm 12.3$ years, $27 \%(\mathrm{n}=4,587)$ female and $21.3 \%(\mathrm{n}=3,733)$ black. The mean Class I and Class II PRA was $7.04 \pm 18.4 \%$ and $5.01 \pm 15.8 \%$, respectively, $78 \%(\mathrm{n}=13,690)$ of patients had more than 3 HLA mismatched, $24.2 \%(\mathrm{n}=4,242)$ gender mismatched and $51.7 \%(\mathrm{n}=9,068)$ were CMV matched with their donors. Approximately $27.1 \%(\mathrm{n}=4,756)$ of patients were bridged to OHT with left ventricular assist devices (LVAD) and the basal median estimated rejection risk score was 8 points [IQR 6,9]. The average donor age was $32.1 \pm 11.3$ years, the mean ischemic time was 3.1 \pm 1.0 hours and the median left ventricle ejection fraction was 60\% $(55,65)$ (Supplementary Table 1).

The average rate of induction therapy utilization was $48.6 \pm 31.6 \%$ (Figure 1), and there were 36, 30 and 34 
centers at low $(<29 \%)$, intermediate $(29-66 \%)$, and high $(>67 \%)$ induction utilization rates groups (Table 1). There were no significant differences in age, gender, pre-OHT blood transfusions, calculated PRAs $>20 \%$ or median pre-OHT rejection risk scores among the groups. Nevertheless, more recipients with elevated creatinine as well as higher rates of HLA and gender mismatch status were in the high tercile. On average, these patients had longer ischemic times and donor-hospital to transplant-center distances. The highest rates of LVAD support were appreciated in the low tercile ( $30.2 \%$ vs $22.4 \%$ vs $28.8 \%, \mathrm{p}<0.001)$.

\section{Posttransplant outcomes}

At the patient-level there were more 30-day mortalities (4.1\% non-induction vs $3.1 \%$ induction, $\mathrm{p}<0.001)$ and fewer patients requiring dialysis after OHT (9.4\% non-induction vs $11.6 \%$ induction, $\mathrm{p}<0.001)$ in the noninduction therapy group. Nevertheless, this difference was not sustained when we compared the center-level outcomes among induction therapy utilization terciles (Figure 2).

Approximately $16.2 \%(\mathrm{n}=2,845)$ of patients had an episode of rejection requiring pharmacological intervention within the first year after OHT. No differences were observed among the groups with $16.2 \%(\mathrm{n}=955)$, $16.3 \%(\mathrm{n}=951)$ and $16.1 \%(\mathrm{n}=939)$ patients developing drug-treated rejection within 1-year in the low, intermediate and high induction terciles, respectively $(\mathrm{p}=0.47)$. Overall 25 centers had rates of rejection above $20 \%$ and these were evenly distributed among the groups (Figure 3). When patients were stratified by their pre-OHT rejection risk score, no center-level correlation was observed between the drug-treated rejection rate and induction therapy utilization $(\mathrm{R}=0.03$ for low, $\mathrm{R}=0.03$ for moderate and $\mathrm{r}=0.04$ for high risk; $\mathrm{p}<0.001$ ) (Figure 4).

\section{Mixed-Effects Model for 1-year Treated-Acute Rejection Rate}

In model A, which assessed the effect of each center as a random parameter, the standard deviation for the center effect for drug-treated rejection within 1-year post OHT was 0.66 [95\% confidence interval (CI) 0.56 , $0.78, \mathrm{p}<0.001$ ] (Table 2). This variability is further evidenced by the finding that 42 of the CIs from the 100 centers did not overlap the average center effect line (Supplementary Figure 1). After adjusting for year of transplantation and recipient and donor risk factors as fixed parameters (model B), the standard deviation for the center effect increased to 0.68 (95\% CI $0.57,0.79, \mathrm{p}<0.001$ ). The variables transplant year, recipient age, recipient gender, and HLA mismatch were significantly associated with 1-year treated rejection. In Model C, after introducing induction therapy at the patient-level as a fixed parameter, no significant association was identified between induction therapy use and 1-year rejection rate (OR 0.93, 95\% CI 0.83-1.03; $\mathrm{p}=0.20)$. The VPC for model $\mathrm{B}$ and $\mathrm{C}$ was $12.5 \%$, further suggesting there is substantial center variation in rejection rates attributable to other unmeasured centers characteristics without any impact by the inclusion of induction therapy parameter.

\section{Mortality at 90-days, 1-Year and 5-years}

The overall rates of mortality for the study population were $5.6 \%(\mathrm{n}=989), 8.7 \%(\mathrm{n}=1,529)$, and $16 \%$ $(\mathrm{n}=2,810)$ at 90 -days, 1 and 5 -years from the OHT, respectively. No differences in the center-level mortality rates at 90 -days $(5.8 \%$ vs $5.2 \%$ vs $5.9 \%, \mathrm{p}=0.1), 1$ year $(8.8 \%$ vs $8.4 \%$ vs $9.0 \%, \mathrm{p}=0.5)$ or at 5 years $(16.2 \%$ vs $15.4 \%$ vs $16.5 \%, \mathrm{p}=0.2$ ) were observed between the low, intermediate and high terciles groups. In riskadjusted Cox regression analysis demonstrated a $13 \%$ reduction in the hazard of death at 90 days (HR $0.87,95 \%$ CI $0.77-0.99 ; \mathrm{p}=0.04)$ in patients who received induction therapy, a relationship that was not appreciated at longer follow-up times (Supplementary Table 2).

\section{Impact of Induction Therapy Type}

The most commonly immunosuppressant used was Basiliximab $(57.2 \%, \mathrm{n}=4,886)$ followed by thymoglobulin $(32.5 \%, \mathrm{n}=2,775)$ (Supplementary Table 3). A sub-analysis that evaluated patients who received induction therapy with either Thymoglobulin or Basiliximab $(n=7,661)$ indicated that risk-adjusted odds were comparable between the type of induction therapy for drug-treated rejection at 1-year, renal failure requiring dialysis, and mortality at all time intervals (Supplementary Table 4) 


\section{Discussion}

\section{Study Findings}

This study confirmed that there is substantial variability in the utilization of induction therapy among US transplant centers. While this would ideally suggest that the highest utilization centers would have recipients with higher baseline risks for post-OHT rejection, instead we found there is a weak correlation between elevated baseline risk scores for rejection and the use of induction therapy. Furthermore, in an average center, induction therapy has no discernible impact on the odds of developing rejection requiring pharmacologic treatment within 1-year of OHT, where there is still a substantial proportion of variability among centers secondary to other unmeasured factors (VPC 17\%). Instead, we found that HLA-mismatch, recipient age, recipient gender, ischemic cardiomyopathy, and unbalanced donor/recipient weight ratios were independent predictors of developing rejection within the first post-operative year. Likewise, the use of induction therapy did not have an impact on mortality at any follow-up interval among centers, although at the patient-level 30- and 90-day mortality was reduced in the induction therapy group. Another key finding was that patients who were more than 3 HLA-mismatched, gender mismatched, and black race, were more concentrated in centers with intermediate or high utilization rates of induction therapy. However, while these variables were statistically different among the utilization groups, the absolute magnitude of the differences were clinically nominal. In addition, taken as a composite assessment of rejection risk, there were no differences in composite risk scores for rejection across groups. As such, certain recipients may have received appropriately risk-stratification for induction therapy, yet with a weak correlation between the receipt of induction therapy and recipients at moderate and high pre-OHT baseline risks of rejection, further emphasis on overall, composite risk-stratification may be warranted during the pre-OHT evaluation. Additionally, we found that patients who received induction therapy tended to have higher rates of acute renal failure requiring dialysis, although this was not sustained at the center-level comparison. These findings may be less strongly associated with induction therapy itself and more likely to be associated with this subset of patients potentially being higher risk for renal failure pre-OHT and receiving induction therapy as a result.

\section{Study Implications}

The major implication of this analysis is that the substantial variability observed in clinical practice across centers with regards to induction therapy utilization in OHT is not explained by differences in the estimated composite risks of rejection at the patient-level, further reflecting the uncertainty behind decision analysis on induction therapy utilization across U.S.

The data also suggest that there are other unmeasured factors that are contributing significantly to differences in 1-year rejection that are not accounted for by induction therapy use. These may include factors such as educational processes surrounding medication compliance or staffing and center resources for monitoring, diagnosing and treating rejection. It is unclear from our analysis what constitutes these center-level factors, although their importance appears significant in the preservation of longitudinal, rejection-free outcomes in OHT recipients.

Prior Studies

While this analysis is the first to explore the impacts of center variability on induction therapy utilization for OHT, similar topics have been explored in the renal and hepatic transplant populations. Bittermann et al (16) found that out of 69,349 liver transplants, only $27 \%$ of these patients received induction therapy and that $65.7 \%$ of the variance in induction therapy utilization was attributed to the transplant center. Dharnidharka et al (17) analyzed 166,776 kidney transplants, in which $81.8 \%$ of recipients were treated with induction therapy although the induction agent utilized was highly variable (Thymoglobulin $58 \%$ and Alemtuzumab $66 \%$ ) and related to center-level characteristics.

For heart transplant recipients the clinical decision of whether to use induction therapy, in which patients to use it in, and which agents to use have been explored without accounting for center variability. A metaanalysis that included 8 randomized controlled trials (18), using various induction therapy agents, found 
the use of induction therapy to be protective against moderate to severe acute rejection (OR $0.795 \%$ CI $0.3-1.7)$. Unfortunately, the high level of heterogeneity $\left(\mathrm{I}^{2}=77 \%\right)$ somewhat limits the interpretability of these results. In a separate Cochrane review (19), Penninga et alincluded 22 RCTs with 1,427 patients and demonstrated that IL-2 receptor antagonists significantly reduced the risks of rejection (RR $0.7395 \%$ CI 0.59 to $0.90 ; \mathrm{I}^{2} 57 \%$ ) when compared to no induction therapy, although there were elevated risks of rejection in patients who received IL-2 antagonists over polyclonal antibody induction therapy (RR 2.43, 95\% CI 1.01 to $5.86 ; \mathrm{I}^{2} 28 \%$ ). Conversely, our study did not demonstrate substantial differences in the odds of rejection at 1-year based on the type of induction therapy utilized. While the studies included in these meta-analyses have a high degree of bias, it is still important to consider the potential different efficacies of the available induction agents. Amin et al investigated the survival of 12,103 OHT recipients from 2006 to 2015 and reported an increase in mortality associated with induction therapy, without identifying any benefits in reductions rejection rates (20). Similarly, a retrospective analysis by Whitson et al (21) of 17,857 OHT recipients from 1987 to 2012 failed to show an overall survival benefit from induction therapy. Both of these studies suggested that the benefit of induction therapy is likely seen in short-term follow-up rather and is also re-enforced by improved patient-level survival at 30- and 90-days in induction therapy recipients in our study, which was mitigated at 1-year and 5-year follow-up among the groups.

\section{Limitations}

This study is subject to the biases inherent in retrospective analysis. We also relied upon the data fidelity of a multicenter registry, which is susceptible to missing and incorrect data entry. Additionally, the lack of accurate information about adherence to maintenance immunosuppression, infections and post-transplant lymphoproliferative disorders prohibited a thorough analysis. There is also a lack of information regarding the specific clinical decisions as to why certain patients may have received induction therapy.

\section{Conclusions}

In this analysis of $17,524 \mathrm{OHT}$ recipients, we demonstrate that the institutional utilization of induction therapy is highly variable across transplant centers and not necessarily attributable to differences in patients' baseline rejection risk. Furthermore, other unmeasured center-level factors appear to contribute to differences in 1-year rejection rates to a higher degree than induction therapy use. The identification of such factors and efforts to better standardize induction therapy use in OHT appear prudent.

\section{Acknowledgements}

The data reported here have been supplied by the United Network for Organ Sharing as the contractor for the Organ Procurement and Transplantation Network. The interpretation and reporting of these data are the responsibility of the authors and in no way should be seen as an official policy of or interpretation by the OPTN or the U.S. Government.

\section{Disclosures}

Arman Kilic is on the medical advisory board from Medtronic, Inc.

Tables

TABLE 1. Characteristics among induction utilization rate groups centers

\begin{tabular}{|c|c|c|c|c|}
\hline Factor & $\begin{array}{l}\text { Low induction } \\
\text { therapy Tercile }(\mathrm{n}= \\
5867)\end{array}$ & $\begin{array}{l}\text { Intermediate } \\
\text { induction Tercile } \\
(\mathrm{n}=5829)\end{array}$ & $\begin{array}{l}\text { High induction } \\
\text { therapy Tercile }(\mathrm{n}= \\
5828)\end{array}$ & $\mathrm{p}$-value \\
\hline $\begin{array}{l}\text { Recipient Age, } \\
\text { mean (SD) }\end{array}$ & $54.1(12.1)$ & $53.5(12.4))$ & $53.9(12.3)$ & 0.05 \\
\hline Gender, female & $1528(26.0 \%)$ & $1532(26.3 \%)$ & $1527(26.2 \%)$ & 0.96 \\
\hline
\end{tabular}




\begin{tabular}{|c|c|c|c|c|}
\hline Factor & $\begin{array}{l}\text { Low induction } \\
\text { therapy Tercile }(\mathrm{n}= \\
5867)\end{array}$ & $\begin{array}{l}\text { Intermediate } \\
\text { induction Tercile } \\
(\mathrm{n}=5829)\end{array}$ & $\begin{array}{l}\text { High induction } \\
\text { therapy Tercile }(\mathrm{n}= \\
5828)\end{array}$ & p-value \\
\hline $\begin{array}{l}\text { Rejection Risk } \\
\text { score, median } \\
\text { (IQR) }\end{array}$ & $8(6-9)$ & $8(6-10)$ & $8(6-9)$ & $<0.001$ \\
\hline $\begin{array}{l}\text { Induction } \\
\text { therapy }\end{array}$ & $767(13.1 \%)$ & $2697(46.3 \%)$ & $5066(86.9 \%)$ & $<0.001$ \\
\hline Basiliximab & $452(7.7 \%)$ & $1,120(41.5 \%)$ & $3,314(65.4 \%)$ & \\
\hline Thymoglobulin & $256(4.4 \%)$ & $1,151(19.7 \%)$ & $1,360(27 \%)$ & \\
\hline Ethnicity & & & & $<0.001$ \\
\hline Caucasian & $3813(65.0 \%)$ & $3819(65.5 \%)$ & $3954(67.8 \%)$ & \\
\hline $\begin{array}{l}\text { African } \\
\text { American }\end{array}$ & $1240(21.1 \%)$ & $1210(20.8 \%)$ & $1283(22.0 \%)$ & \\
\hline Hispanic & $551(9.4 \%)$ & $509(8.7 \%)$ & $324(5.6 \%)$ & \\
\hline $\begin{array}{l}\text { Body Mass } \\
\text { Index }(\mathrm{kg} / \mathrm{m} 2)\end{array}$ & $27.4(4.9)$ & $27.1(4.8)$ & $27.5(5.1)$ & $<0.001$ \\
\hline Diagnosis & & & & $<0.001$ \\
\hline $\begin{array}{l}\text { Non-Ischemic } \\
\text { Dilated Car- } \\
\text { diomyopathy }\end{array}$ & $2987(50.9 \%)$ & $3046(52.3 \%)$ & $3056(52.4 \%)$ & \\
\hline $\begin{array}{l}\text { Ischemic Car- } \\
\text { diomyopathy }\end{array}$ & $2167(36.9 \%)$ & $1989(34.1 \%)$ & $2104(36.1 \%)$ & \\
\hline Congenital & $127(2.2 \%)$ & 129 (2.2\%) & $188(3.2 \%)$ & \\
\hline $\begin{array}{l}\text { Restrictive } \\
\text { Cardiomyopa- } \\
\text { thy }\end{array}$ & $89(1.5 \%)$ & $100(1.7 \%)$ & $53(0.9 \%)$ & \\
\hline $\begin{array}{l}\text { Hypertrophic } \\
\text { Cardiomyopa- } \\
\text { thy }\end{array}$ & $122(2.1 \%)$ & $182(3.1 \%)$ & $135(2.3 \%)$ & \\
\hline Valvular & $179(3.1 \%)$ & $218(3.7 \%)$ & $180(3.1 \%)$ & \\
\hline Status 1A & $3812(65.0 \%)$ & $3716(63.8 \%)$ & $3696(63.4 \%)$ & 0.18 \\
\hline $\begin{array}{l}\text { Class I PRA > } \\
20 \%\end{array}$ & $321(5.5 \%)$ & $337(5.8 \%)$ & $354(6.1 \%)$ & 0.38 \\
\hline $\begin{array}{l}\text { Class II PRA } \\
>20 \%\end{array}$ & $228(3.9 \%)$ & $263(4.5 \%)$ & $242(4.2 \%)$ & 0.24 \\
\hline $\begin{array}{l}\text { Diabetes } \\
\text { Mellitus }\end{array}$ & $1726(29.4 \%)$ & $1571(27.0 \%)$ & $1647(28.3 \%)$ & 0.01 \\
\hline $\begin{array}{l}\text { Intra-Aortic } \\
\text { Balloon Pump }\end{array}$ & $312(5.3 \%)$ & $201(3.4 \%)$ & $320(5.5 \%)$ & $<0.001$ \\
\hline $\begin{array}{l}\text { Inotropes at } \\
\text { listing }\end{array}$ & $1809(30.8 \%)$ & $1969(33.8 \%)$ & $2083(35.7 \%)$ & $<0.001$ \\
\hline $\begin{array}{l}\text { Serum } \\
\text { Creatinine in } \\
\mathrm{mg} / \mathrm{dL} \text {, mean } \\
\text { (SD) }\end{array}$ & $1.20(.4)$ & $1.22(.4)$ & $1.24(.5)$ & $<0.001$ \\
\hline $\begin{array}{l}\text { Pre-Transplant } \\
\text { Mechanical } \\
\text { Ventilation }\end{array}$ & $36(0.6 \%)$ & $82(1.4 \%)$ & $83(1.4 \%)$ & $<0.001$ \\
\hline $\begin{array}{l}\text { Transfusions } \\
\text { While Listed }\end{array}$ & $1350(23.0 \%)$ & 1301 (22.3\%) & $1406(24.1 \%)$ & 0.06 \\
\hline
\end{tabular}




\begin{tabular}{|c|c|c|c|c|}
\hline Factor & $\begin{array}{l}\text { Low induction } \\
\text { therapy Tercile }(\mathrm{n}= \\
5867)\end{array}$ & $\begin{array}{l}\text { Intermediate } \\
\text { induction Tercile } \\
(\mathrm{n}=5829)\end{array}$ & $\begin{array}{l}\text { High induction } \\
\text { therapy Tercile }(\mathrm{n}= \\
5828)\end{array}$ & p-value \\
\hline $\begin{array}{l}\text { Pre-Transplant } \\
\text { Dialysis }\end{array}$ & $52(0.9 \%)$ & $59(1.0 \%)$ & $39(0.7 \%)$ & 0.13 \\
\hline $\begin{array}{l}\text { Left } \\
\text { Ventricular } \\
\text { Assist Device } \\
\text { Support }\end{array}$ & $1774(30.2 \%)$ & $1305(22.4 \%)$ & $1677(28.8 \%)$ & $<0.001$ \\
\hline Heartmate 2 & $1466(25.0 \%)$ & $949(16.3 \%)$ & $1246(21.4 \%)$ & \\
\hline Heartmate 3 & $69(1.2 \%)$ & $43(0.7 \%)$ & $51(0.9 \%)$ & \\
\hline HeartWare & $239(4.1 \%)$ & $313(5.4 \%)$ & $380(6.5 \%)$ & \\
\hline $\begin{array}{l}\text { HLA mismatch } \\
(>3)\end{array}$ & $4200(71.6 \%)$ & $4761(81.7 \%)$ & $4729(81.1 \%)$ & $<0.001$ \\
\hline $\begin{array}{l}\text { Gender } \\
\text { mismatch }\end{array}$ & $4359(74.3 \%)$ & $4392(75.3 \%)$ & $4531(77.7 \%)$ & $<0.001$ \\
\hline CMV match & $3062(52.2 \%)$ & $3049(52.3 \%)$ & $2957(50.7 \%)$ & 0.17 \\
\hline $\begin{array}{l}\text { Donor-to- } \\
\text { Recipient } \\
\text { Weight Ratio, } \\
\text { mean (SD) }\end{array}$ & $1.01(.24)$ & $1.03(.24)$ & $1.01(.23)$ & $<0.001$ \\
\hline
\end{tabular}

Table 2. Mixed effect logistic regression model for treated acute rejection at 1-year post-OHT.

\begin{tabular}{|c|c|c|c|c|}
\hline & $\begin{array}{l}\text { Fixed-Effect } \\
\text { Parameter-Odds } \\
\text { Ratio OR (95\% } \\
\text { CI) }\end{array}$ & p-value & $\begin{array}{l}\text { Random-Effect } \\
\text { Parameter- } \\
\text { Standard } \\
\text { deviation (95\% } \\
\text { CI) }\end{array}$ & p-value \\
\hline Model A & Model A & Model A & Model A & \\
\hline Individual center & & & $0.66(0.56-0.78)$ & $<0.001$ \\
\hline Model B & Model B & Model B & Model B & \\
\hline Individual center & & & $0.68(0.57-0.79)$ & $<0.001$ \\
\hline Age & $0.98(0.97-0.98)$ & $<0.001$ & & \\
\hline $\begin{array}{l}\text { Gender Female } \\
(Y e s / N o)\end{array}$ & $1.36(1.24-1.50)$ & $<0.001$ & & \\
\hline Transplant year & $0.95(0.93-0.97)$ & $<0.001$ & & \\
\hline $\begin{array}{l}\text { Heart failure } \\
\text { diagnosis }\end{array}$ & $\begin{array}{l}\text { Dilated as } \\
\text { reference }\end{array}$ & & & \\
\hline Ischemic & $1.13(1.02-1.25)$ & 0.01 & & \\
\hline Cardiomyopathy & & & & \\
\hline Congenital & $1.01(0.78-1.32)$ & 0.88 & & \\
\hline Restrictive & $1.04(0.69-1.46)$ & 0.94 & & \\
\hline Hypertrophied & $0.91(0.69-1.20)$ & 0.51 & & \\
\hline Valvular & $0.89(0.69-1.14)$ & 0.37 & & \\
\hline $\begin{array}{l}\text { African American } \\
\text { (Yes/No) }\end{array}$ & $1.04(0.94-1.16$ & 0.40 & & \\
\hline $\begin{array}{l}\text { PRA Class II } \\
>20 \%\end{array}$ & $1.12(0.90-1.40)$ & 0.29 & & \\
\hline
\end{tabular}




\begin{tabular}{|c|c|c|c|c|}
\hline & $\begin{array}{l}\text { Fixed-Effect } \\
\text { Parameter-Odds } \\
\text { Ratio OR (95\% } \\
\text { CI) }\end{array}$ & p-value & $\begin{array}{l}\text { Random-Effect } \\
\text { Parameter- } \\
\text { Standard } \\
\text { deviation (95\% } \\
\text { CI) }\end{array}$ & p-value \\
\hline $\begin{array}{l}\text { HLA mismatch, } 3 \\
\text { or more (Yes/No) }\end{array}$ & $1.23(1.09-1.39)$ & 0.001 & \multirow{21}{*}{$\begin{array}{l}\text { Model C } \\
0.67(0.57-0.79)\end{array}$} & \multirow{21}{*}{$<0.001$} \\
\hline $\begin{array}{l}\text { Donor:Recipient } \\
\text { weight ratio }\end{array}$ & $0.80(0.67-0.96)$ & 0.02 & & \\
\hline Donor age & $0.99(0.99-1.01)$ & 0.20 & & \\
\hline $\begin{array}{l}\text { Average } \\
\text { transplant per } \\
\text { year }\end{array}$ & $1.00(0.99-1.01)$ & 0.80 & & \\
\hline Model C & Model C & Model C & & \\
\hline Individual center & & & & \\
\hline Age & $0.98(0.97-0.98)$ & $<0.001$ & & \\
\hline $\begin{array}{l}\text { Gender Female } \\
(Y e s / N o)\end{array}$ & $1.36(1.24-1.50)$ & $<0.001$ & & \\
\hline Transplant year & $0.95(0.93-0.97)$ & $<0.001$ & & \\
\hline $\begin{array}{l}\text { Heart failure } \\
\text { diagnosis }\end{array}$ & $\begin{array}{l}\text { Dilated as } \\
\text { reference }\end{array}$ & & & \\
\hline $\begin{array}{l}\text { Ischemic } \\
\text { Sardiomyonathy }\end{array}$ & $1.13(1.02-1.25)$ & 0.01 & & \\
\hline Cardiomyopathy & & & & \\
\hline Congenital & $1.02(0.78-1.32)$ & 0.87 & & \\
\hline Restrictive & $1.01(0.70-1.48)$ & 0.91 & & \\
\hline Hypertrophied & $0.91(0.69-1.20)$ & 0.53 & & \\
\hline Valvular & $0.89(0.69-1.14)$ & 0.37 & & \\
\hline $\begin{array}{l}\text { African American } \\
\text { (Yes/No) }\end{array}$ & $1.04(0.94-1.16$ & 0.39 & & \\
\hline $\begin{array}{l}\text { HLA mismatch, } \\
>3(\text { Yes/No })\end{array}$ & $1.23(1.01-1.39)$ & 0.001 & & \\
\hline $\begin{array}{l}\text { Donor:Recipient } \\
\text { weight ratio }\end{array}$ & $0.79(0.66-0.95)$ & 0.01 & & \\
\hline $\begin{array}{l}\text { Average } \\
\text { transplant per } \\
\text { year }\end{array}$ & $1.00(0.99-1.01)$ & 0.79 & & \\
\hline $\begin{array}{l}\text { Induction } \\
\text { Therapy }\end{array}$ & $0.93(0.83-1.03)$ & 0.20 & & \\
\hline
\end{tabular}

\section{Figures}

Figure 1. - Histogram showing induction therapy use (\%) by transplant centers

Figure 2. - Postoperative outcomes stratified by induction therapy terciles

Figure 3. - Treated-acute rejection rate at 1-year post-OHT stratified by center-level induction therapy terciles. Each circle represents an individual center.

Figure 4. - Center-level correlation between treated-acute rejection rate at 1 year and induction therapy utilization stratified by the baseline recipient pre-OHT rejection risk scores. Each circle represents an individual center. 


\section{References}

1. Enderby C, Keller CA. An overview of immunosuppression in solid organ transplantation. Am J Manag Care. 2015 Jan;21(1 Suppl):s12-23.

2. Zuckermann A, Schulz U, Deuse T, Ruhpawar A, Schmitto JD, Beiras-Fernandez A, et al. Thymoglobulin induction in heart transplantation: patient selection and implications for maintenance immunosuppression. Transpl Int. 2015 Mar;28(3):259-69.

3. Wang S-S, Chou N-K, Chi N-H, Huang S-C, Wu I-H, Wang C-H, et al. The survival of heart transplant recipients using cyclosporine and everolimus is not inferior to that using cyclosporine and mycophenolate. Transplant Proc. 2010 Apr;42(3):938-9.

4. Weber BN, Kobashigawa JA, Givertz MM. Evolving Areas in Heart Transplantation. JACC Hear Fail. 2017 Dec 1;5(12):869-78.

5. Almenar L, García-Palomar C, Martínez-Dolz L, Chamorro C, Moro J, Zorio E, et al. Influence of induction therapy on rejection and survival in heart transplantation. Transplant Proc. 2005 Nov;37(9):4024-7.

6. Mehra MR, Zucker MJ, Wagoner L, Michler R, Boehmer J, Kovarik J, et al. A Multicenter, Prospective, Randomized, Double-Blind Trial of Basiliximab in Heart Transplantation. J Hear Lung Transplant. 2005 Sep 1;24(9):1297-304.

7. Hershberger RE, Starling RC, Eisen HJ, Bergh C-H, Kormos RL, Love RB, et al. Daclizumab to prevent rejection after cardiac transplantation. N Engl J Med. 2005 Jun 30;352(26):2705-13.

8. Hao W-J, Zong H-T, Cui Y-S, Zhang Y. The Efficacy and Safety of Alemtuzumab and Daclizumab Versus Antithymocyte Globulin During Organ Transplantation: A Meta-Analysis. Transplant Proc. 2012 Dec 1;44(10):2955-60.

9. Higgins R, Kirklin JK, Brown RN, Rayburn BK, Wagoner L, Oren R, et al. To induce or not to induce: Do patients at greatest risk for fatal rejection benefit from cytolytic induction therapy? J Hear Lung Transplant. 2005 Apr;24(4):392-400.

10. Kilic A, Weiss ES, Allen JG, Conte J V., Shah AS, Baumgartner WA, et al. Simple Score to Assess the Risk of Rejection After Orthotopic Heart Transplantation. Circulation. 2012 Jun 19;125(24):3013-21.

11. Costanzo MR, Costanzo MR, Dipchand A, Starling R, Anderson A, Chan M, et al. The International Society of Heart and Lung Transplantation Guidelines for the care of heart transplant recipients. Vol. 29, The Journal of Heart and Lung Transplantation. 2010. p. 914-56.

12. Shuhaiber JH, Moore J, Dyke DB. The effect of transplant center volume on survival after heart transplantation: A multicenter study. J Thorac Cardiovasc Surg. 2010;

13. Arnaoutakis GJ, George TJ, Allen JG, Russell SD, Shah AS, Conte J V., et al. Institutional volume and the effect of recipient risk on short-term mortality after orthotopic heart transplant. J Thorac Cardiovasc Surg. 2012 Jan;143(1):157-167.e1.

14. Kilic A, Weiss ES, Yuh DD, Shah AS, Cameron DE, Baumgartner WA, et al. Institutional Factors Beyond Procedural Volume Significantly Impact Center Variability in Outcomes After Orthotopic Heart Transplantation. Ann Surg. 2012 Oct;256(4):616-23.

15. Austin PC, Merlo J. Intermediate and advanced topics in multilevel logistic regression analysis. Stat Med. 2017 Sep 10;36(20):3257-77.

16. Bittermann T, Hubbard RA, Lewis JD, Goldberg DS. The use of induction therapy in liver transplantation is highly variable and is associated with posttransplant outcomes. Am J Transplant. 2019 Dec 17;19(12):331927. 
17. Dharnidharka VR, Naik AS, Axelrod DA, Schnitzler MA, Zhang Z, Bae S, et al. Center practice drives variation in choice of US kidney transplant induction therapy: a retrospective analysis of contemporary practice. Transpl Int. 2018 Feb;31(2):198-211.

18. Briasoulis A, Inampudi C, Pala M, Asleh R, Alvarez P, Bhama J. Induction immunosuppressive therapy in cardiac transplantation: a systematic review and meta-analysis. Heart Fail Rev. 2018 Sep 13;23(5):641-9.

19. Penninga L, Møller CH, Gustafsson F, Gluud C, Steinbrüchel DA. Immunosuppressive T-cell antibody induction for heart transplant recipients. Cochrane Database Syst Rev. 2013 Dec 2;

20. Amin AA, Araj FG, Ariyamuthu VK, Drazner MH, Ayvaci MUS, Mammen PPA, et al. Impact of induction immunosuppression on patient survival in heart transplant recipients treated with tacrolimus and mycophenolic acid in the current allocation era. Clin Transplant. 2019;

21. Whitson BA, Kilic A, Lehman A, Wehr A, Hasan A, Haas G, et al. Impact of induction immunosuppression on survival in heart transplant recipients: a contemporary analysis of agents. Clin Transplant. 2015 Jan;29(1):9-17.

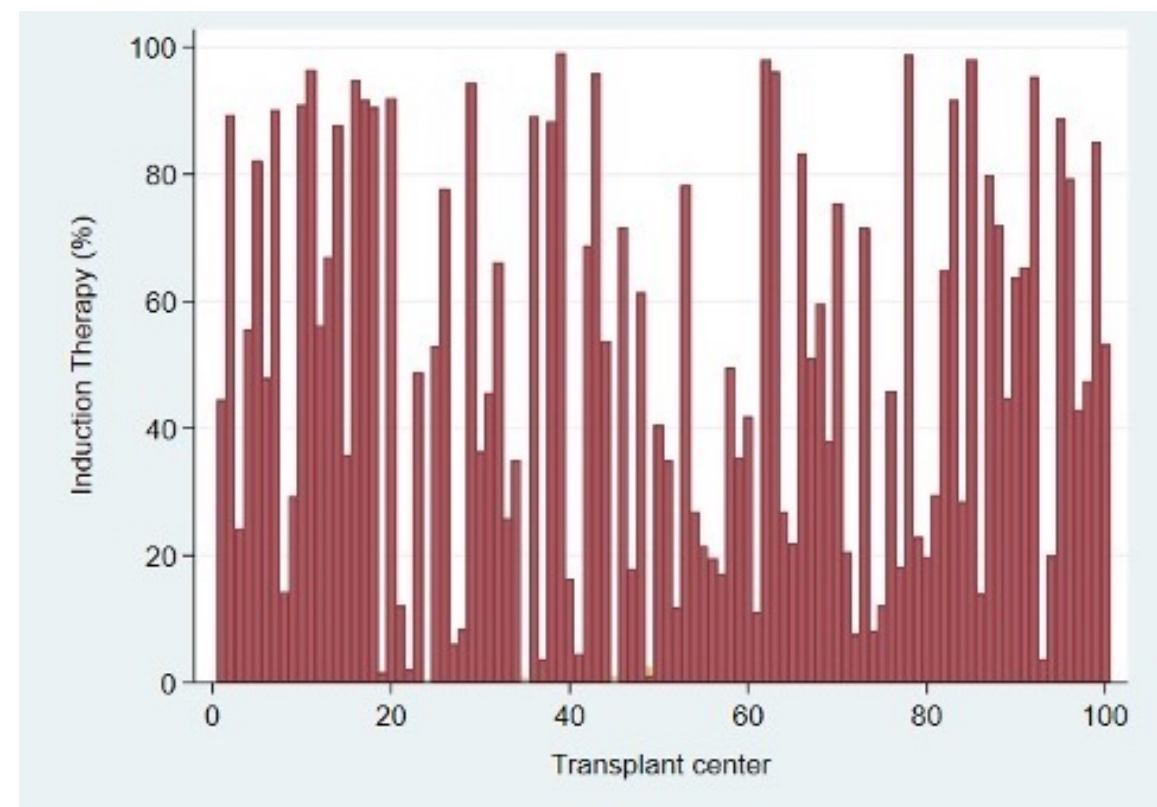



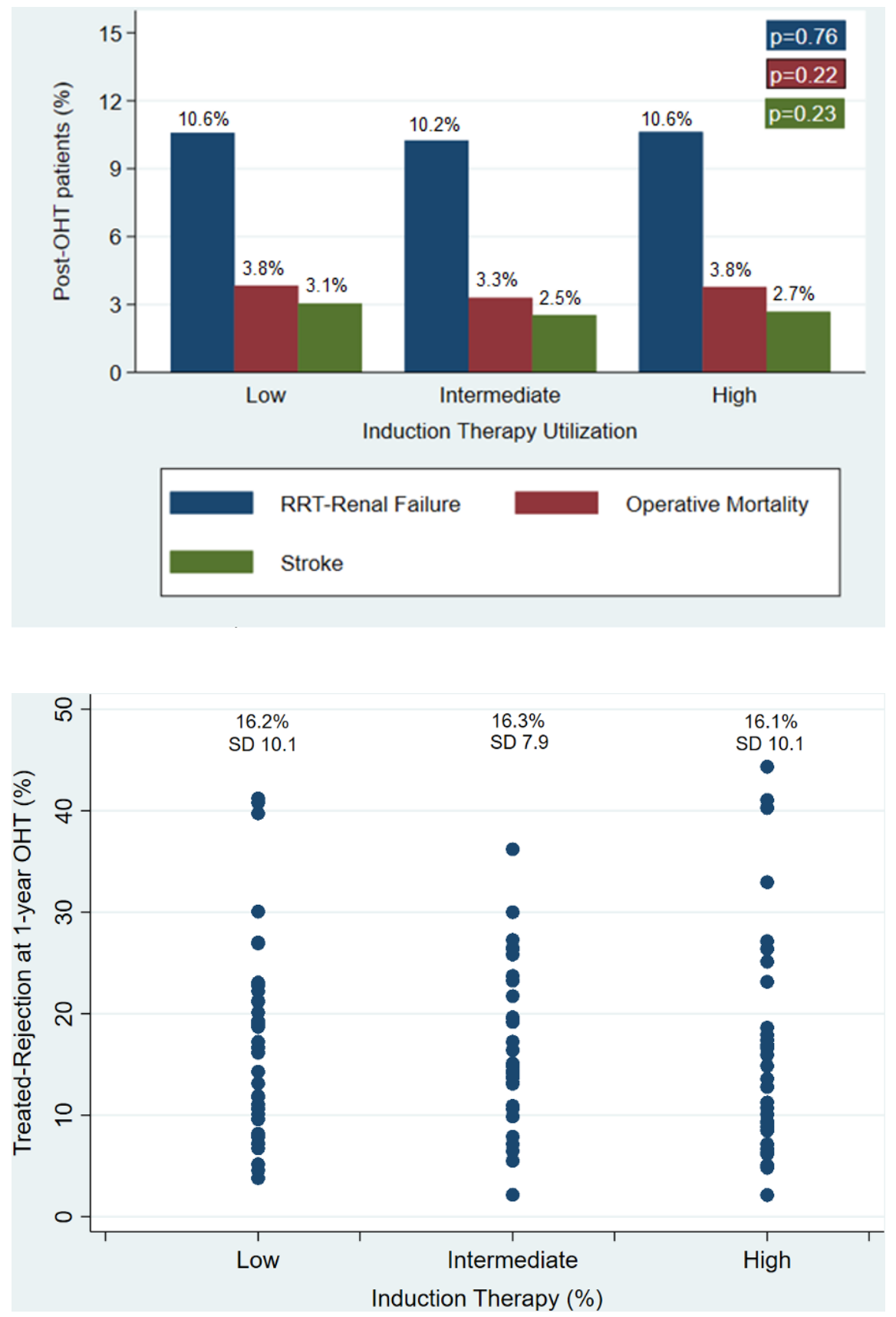

\section{Hosted file}

Figure 4 Risk Stratified Drug-Treated rejection.tiff available at https://authorea.com/users/ 330548/articles/457295-nationwide-variability-in-the-use-of-induction-immunosuppressionfor-adult-heart-transplantation 